\title{
Oxidized Low-Density Lipoprotein Induces Apoptosis in Endothelial Progenitor Cells by Inactivating the Phosphoinositide 3-Kinase/Akt Pathway
}

\author{
Guodong Tie $^{\mathrm{a}}$ Jinglian Yan ${ }^{\mathrm{a}}$ Yagai Yang $^{\mathrm{b}}$ Brian D. Park $^{\mathrm{a}}$ Julia A. Messina ${ }^{\mathrm{a}}$ \\ Robert L. Raffai ${ }^{b}$ Philip T. Nowicki ${ }^{a}$ Louis M. Messina ${ }^{a}$ \\ aDepartment of Surgery, University of Massachusetts Medical School, Worcester, Mass., and \\ ${ }^{b}$ Department of Surgery, University of California San Francisco, San Francisco, Calif., USA
}

\section{Key Words}

Akt $\cdot$ Apoptosis $\cdot$ Endothelial progenitor cell $\cdot$ Oxidized

low-density lipoprotein $\cdot$ Phosphoinositide 3-kinase

\begin{abstract}
We tested the hypothesis that oxidized low-density lipoprotein (oxLDL)-induced inactivation of Akt within endothelial progenitor cells (EPCS) is mediated at the level of Phosphoinositide 3-kinase (PI3K), specifically by nitrosylation of the $\mathrm{p} 85$ subunit of $\mathrm{PI} 3 \mathrm{~K}$, and that this action is critical in provoking oxLDL-induced EPC apoptosis. Hypercholesterolemic ApoE null mice had a significant reduction of the phosphorylated Akt ( $p-A k t) / A k t$ ratio in EPCs, as well as a greater percentage of apoptosis in these cells than EPCs isolated from wild-type (WT) C57BI/6 mice. EPCs were isolated from WT spleen and exposed to oxLDL in vitro. oxLDL increased $\mathrm{O}_{2}^{-}$and $\mathrm{H}_{2} \mathrm{O}_{2}$ in these cells and induced a dose- and timedependent reduction in the $\mathrm{p}$-Akt/Akt ratio and increase in EPC apoptosis. These effects were significantly reduced by the antioxidants superoxide dismutase, L-NAME, epicatechin and FeTPPs. oxLDL also induced nitrosylation of the p85 subunit of PI3K and subsequent dissociation of the p85 and p110 subunits, an effect significantly reduced by all the antioxidant agents tested. EPC transfection with a constitutively ac-
\end{abstract}

tive Akt isoform (Ad-myrAkt) significantly reduced oxLDLinduced apoptosis of WTEPCs. The present findings indicate that oxLDL disrupts the PI3K/Akt signaling pathway at the level of p85 in EPCs. This dysfunction can be reversed by ex vivo antioxidant therapy.

Copyright $\odot 2010$ S. Karger AG, Basel

\section{Introduction}

Endothelial progenitor cells (EPCs) play a critical role in postischemic vascular repair [1-3]. These cells, found in bone marrow and peripheral blood as well as in organs such as the spleen and liver, home to the sites of vascular injury in response to several chemokines [2-4]. Originally, EPCs were thought to participate in vascular repair by differentiation and subsequent incorporation into the vessel as endothelial cells [1]. It is now believed that EPCs function in a paracrine manner to promote growth of surrounding tissue [5]. Clinical conditions that compromise EPC function impair their neovascularization potential and thus place a patient at greater risk of cardiovascular disease; indeed, the number and functional capacity of EPCs in peripheral blood are excellent predictors of adverse cardiovascular events [6].

\section{KARGER}

(C) 2010 S. Karger AG, Basel

Fax +41613061234 E-Mail karger@karger.ch www.karger.com www.karger.com/jvr
Dr. Louis M. Messina

Department of Surgery

University of Massachusetts Medical School

55 Lake Avenue North, Worcester, MA 01655 (USA)

Tel. +1 508856 5599, Fax +1 508856 8329, E-Mail Louis.Messina@ umassmemorial.org 
Oxidized low-density lipoprotein (oxLDL) is taken up by EPCs in a receptor-dependent manner wherein it generates oxidative stress [7]. This effect is mediated by at least three mechanisms: activation of NADPH oxidase [8], uncoupling of endothelial nitric oxide synthase (eNOS) [9] and generation of lipid peroxide radicals within the plasma membrane that establish an oxidative chain reaction [10]. oxLDL-induced oxidative stress can lead to cell necrosis or apoptosis [7]. Catalase and N-acetylcysteine reduce both the oxidant stress and apoptosis produced by oxLDL, although superoxide dismutase (SOD) does not [7]. Collectively, these observations suggest that oxLDL may impair EPC survival, a circumstance that would impair their participation in postischemic vascular repair.

The phosphoinositide 3-kinase (PI3K)/Akt pathway is a ubiquitous signaling system that is requisite for normal EPC function [11]. PI3K-induced phosphorylation of Akt leads to downstream activation of eNOS and the production of nitric oxide (NO) [12], a critical stimulus for EPC differentiation toward an endothelial cell phenotype and for postischemic vascular repair [13]. oxLDL can impair Akt activation in EPCs [14]. However, the mechanism for this effect and the role of Akt inhibition in the induction of EPC apoptosis have not been fully clarified. The goal of this study was to test the hypothesis that oxLDL-induced inactivation of Akt is mediated at the level of PI3K, specifically by nitration of the p85 subunit of PI3K, and that this action is critical in provoking oxLDL-induced EPC apoptosis.

\section{Materials and Methods}

\section{Reagents and Antibodies}

Native LDL (nLDL), epicatechin, L-NAME, SOD-PEG, dichlorofluorescein diactetate (DCF), dihydroethidine (DHE) and Histopaque 1083 were purchased from Sigma-Aldrich (St. Louis, Mo., USA). Monoclonal antibodies were purchased as follows: lectin, $\beta$-actin (Sigma-Aldrich); phosphorylated Akt (p-Akt), Akt, phosphorylated GSK3 $\alpha$ and GSK3 $\alpha$ (Cell Signaling Technology, Beverly, Mass., USA); p85 and p110 subunits of PI3K (Upstate Biotechnology, Lake Placid, N.Y., USA); nitrotyrosine (Cayman Biochemical, Ann Arbor, Mich., USA); KDR, AC133, CD34 (eBioscience, San Diego, Calif., USA); CD31 (BD Pharmigen, San Jose, Calif., USA); vWF (Abcam, Cambridge, Mass., USA); Dil-Ac-LDL (Biomedical Technologies, Stoughton, Mass., USA); eNOS (BD Transduction Laboratories, Lexington, K.Y., USA); VE-cadherin (Santa Cruz Biotechnology, Santa Cruz, Calif., USA). Secondary antibodies were obtained from Jackson ImmunoResearch Laboratories (West Grove, Pa., USA). 5,10,15,20-tetrakis(4-sulfonatophenyl) porphyrinato iron (III) chloride (FeTPPs) was purchased from Calbiochem EMD (San Diego, Calif., USA). The TUNEL apoptosis detection kit was purchased from Chemicon International (Temecula, Calif., USA). All other reagents were of analytical grade and purchased from Sigma-Aldrich.

Care and Use of Laboratory Animals

$\mathrm{C} 57 \mathrm{Bl} / 6$ and $A p o E^{t m 1 U n c}$ (ApoE) mice were purchased from Jackson Laboratories (Bar Harbor, Me., USA). The chow (Prolab ${ }^{\circledR}$ Isopro $^{\circledR}$ RMH3000 5P76) contained $5.4 \%$ fat by weight (14\% of total calories as fat). ApoE mice were generated on a C57Bl/6 background and when fed the aforementioned diet developed significant hypercholesterolemia with elevated oxLDL [15]. All mice were housed in a standard vivarium facility and allowed free access to chow and water. Mice were anesthetized with $1 \%$ isoflurane prior to phlebotomy. The University of California San Francisco and the University of Massachusetts Medical School Institutional Animal Care and Use Committees approved the protocol.

\section{Transfection of EPCs}

The adenovirus encoding myrAkt cDNA (Ad-myrAkt) was a generous gift from Kenneth Walsh, MD (Boston University School of Medicine). The virus was propagated and titrated in 293 cells. myrAkt is a constitutively active Akt mutant and has the cSrc myrisolyation sequence fused in-frame to the NB terminus of the wild-type (WT) Akt. Ad-DLE1, an empty adenovirus construct, was used as the control vector in transfections. All adenovirus stock was stored at $-80^{\circ} \mathrm{C}$ and thawed immediately before use. Adenoviral stocks were diluted in sterile phosphate-buffered saline (PBS) to achieve a final concentration of $10^{10}$ plaque-forming units/ml. Experiments were carried out $48 \mathrm{~h}$ after transfection.

Isolation and Identification of EPCs

Spleens were used as the source of EPCs as they offered a readily available, reproducible, and plentiful source of these cells, as has been described by others [16]. The spleens were explanted and mechanically minced using a syringe plunger and a $40-\mu \mathrm{m}$ nylon cell strainer (BD Falcon). The resulting cell suspension was laid over Histopaque 1083 and centrifuged at $400 \mathrm{~g}$ for $30 \mathrm{~min}$. A band of mononuclear cells (MNCs) in the middle of tubes were collected, washed and repelleted twice. Before seeded on fibronectincoated plates, MNCs were washed 2 times with PBS. Spleen MNC counts were adjusted and $5 \times 10^{6}$ cells were plated on fibronectincoated 60 -mm plates, in $4 \mathrm{ml}$ endothelial growth medium supplemented with hydrocortisone, hEGF, VEGF, hFGF-B, IGF-1, ascorbic acid, heparin and 2\% fetal bovine serum (EGM-2; Cambrex, East Rutherford, N.J., USA). After 7 days the identity of adherent cells as EPC was confirmed in some wells by incubation with $2.4 \mu \mathrm{g} / \mathrm{ml}$ Dil-Ac-LDL for $1 \mathrm{~h}$, followed by fixation in $2 \%$ paraformaldehyde and counterstaining with FITC-labeled lectin. EPCs were identified as cells labeled with Dil-Ac-LDL and lectin. Using this method, we noted that approximately $50 \%$ of the adherent cells stained positive for Dil-Ac-LDL and lectin. Other wells were trypsinized and the cells were stained with monoclonal antibodies for KDR, AC133, eNOS, CD31, CD34, VE-cadherin and vWF to identify them as EPCs by FACS analysis. FACS sorting for $\mathrm{KDR}^{+} \mathrm{CD} 31^{+} \mathrm{AC} 133^{+}$was used to isolate EPC prior to their use in protocols. By this sorting method, we generally recovered approximately $7 \times 10^{5}$ cells from a well originally seeded with $5 \times 10^{6}$ spleen MNCs. 
Fig. 1. Presence of apoptosis and Akt phosphorylation in EPCs harvested from wildtype and $\mathrm{ApoE}^{-/-}$mice. Mononuclear cells were obtained from the spleens of wild-type and $\mathrm{ApoE}^{-/-}$mice by gradient centrifugation and then separated by FACS sorting to obtain CD34+ AC133+ KDR+ cells; these cells were expanded ex vivo for $48 \mathrm{~h}$ in serum-free medium. These cells were evaluated to determine EPC apoptosis and Akt expression. a Percentage of apoptotic cells determined by TUNEL staining; mean \pm $\mathrm{SD}, \mathrm{n}=3$; $^{*} \mathrm{p}<0.05$ versus wild-type group. b Ratio of p-Akt / total Akt in EPC cell lysates. Densities of the Akt bands were first corrected with respect to $\beta$-actin and then the p-Akt/total Akt expression ratio calculated. The ratio of the wild-type group was assigned a value of 1.0 for statistical analysis. Data are presented as mean $\pm \mathrm{SD}, \mathrm{n}=$ $3 ;^{*} \mathrm{p}<0.05$ versus wild-type group.

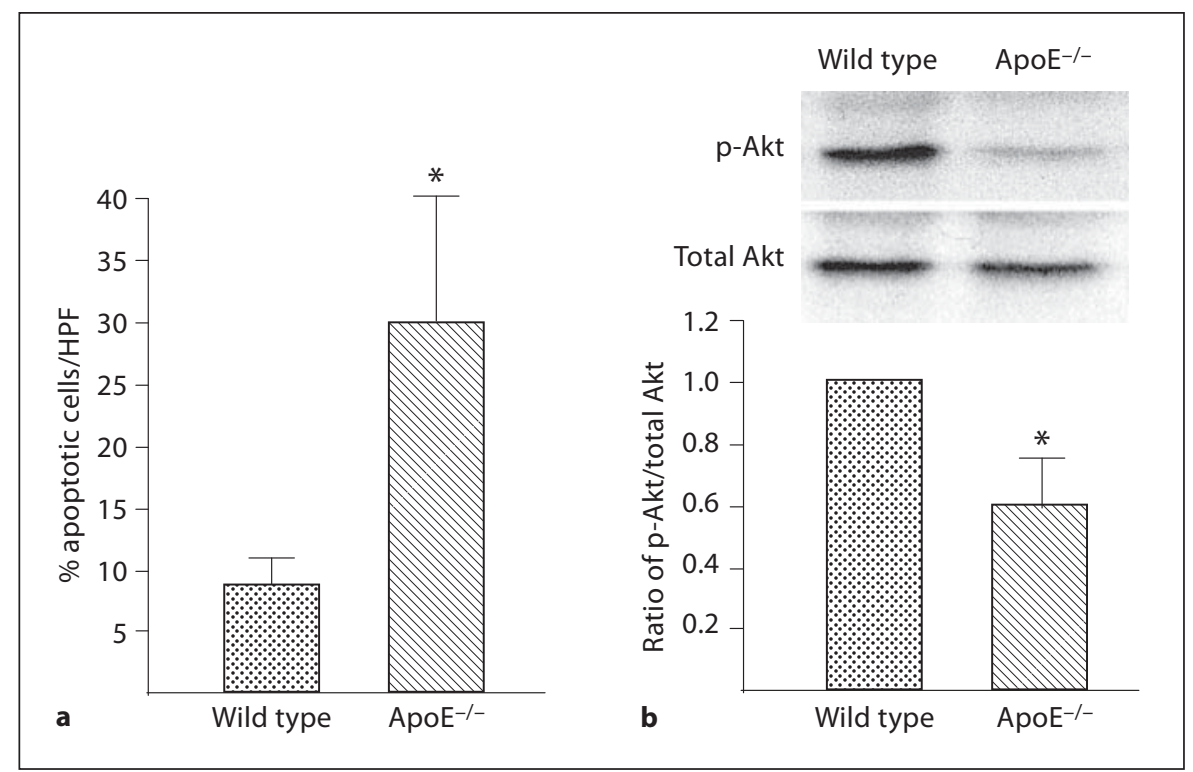

In a second protocol, adherent cells were trypsinized $(0.5 \%$ trypsin) and stained with monoclonal antibodies for KDR, CD34, AC133, CD31, eNOS, VE-cadherin and vWF followed by FACS sorting. Approximately $7 \times 10^{5}$ cells from each well were sorting as EPCs using this approach.

\section{Preparation of oxLDL}

nLDL was incubated with $\mathrm{CuSO}_{4}(10 \mu \mathrm{M})$ at $37^{\circ} \mathrm{C}$ for $24 \mathrm{~h}$. The material was dialyzed against a sterile solution of $\mathrm{NaCl} 150 \mathrm{mM}$, EDTA $1 \mathrm{~mm}$ and polymixin B $100 \mu \mathrm{g} / \mathrm{ml}$ (pH 7.4). The presence of oxLDL was confirmed by agarose gel electrophoresis and by generation of thiobarbituric acid.

\section{Determination of Intracellular Reactive Oxygen Species}

Upon completion of the experimental protocol cells were washed with PBS and then incubated with either DCF or DHE for 30 min. These reagents primarily react with $\mathrm{H}_{2} \mathrm{O}_{2}$ and $\mathrm{O}_{2}^{-}$, respectively, although some cross-reactivity with other reactive oxygen species occur. The slide was counterstained with 4',6-diamidino2-phenylindole (DAPI) to detect nuclei. Fluorescence microscopy was used to determine uptake of the fluoroprobes by EPCs. Cells in 10 high power fields $(400 \times)$ were counted by a blinded observer and the average calculated. Data for DCF and DHE were expressed as a percentage of the total number of cells in the field.

\section{Determination of Intracellular Nitrotyrosine}

EPC were seeded on 4 -well chamber slides at a density of $5 \times$ $10^{4}$ cells/well. After completion of the experimental protocol, cells were fixed with $4 \%$ paraformaldehyde for $10 \mathrm{~min}$ and then incubated with nitrotyrosine antibody overnight $\left(4^{\circ} \mathrm{C}\right)$. This $1^{\circ}$ antibody was detected by FITC-conjugated $2^{\circ}$ antibody. The slide was counterstained with DAPI. Fluorescence microscopy was used to determine uptake of the fluoroprobes by EPCs. In each study, cells in 10 high power fields $(400 \times)$ were counted by a blinded observer and the average calculated. Nitrotyrosine data were expressed as a percentage of the total number of cells in the field.

\section{Determination of EPC Apoptosis}

EPCs were seeded on 4 -well chamber slides at a density of $5 \times$ $10^{4}$ cells/well. After completion of the experimental protocol, cells were fixed with $1 \%$ paraformaldehyde for $10 \mathrm{~min}$ and then labeled using the Apotag Plus apoptosis detection reagent (TUNEL staining), followed by counter staining with DAPI. In each study, cells from 10 high power fields $(400 \times)$ were counted by a blinded observer and the average calculated. TUNEL data were expressed as the percentage of the total number of cells in each field.

\section{Western Blotting}

EPCs were lysed in modified NP40 lysis buffer (Tris $\mathrm{HCl} 10$ mM, pH 7.4; EGTA 1 mM; sucrose 0.25 mM; with phenylmethanesulphonyl fluoride and aprotinin). Supernatant protein levels were determine by a bicinchoninic acid assay (Pierce, Rockford, Ill., USA). Fifty microgram of each protein sample was resolved on a $10 \%$ SDS-PAGE gel, transferred to a nitrocellulose membrane, and probed with $1^{\circ}$ antibody. A horseradish peroxidase $2^{\circ}$ antibody was then applied and the membrane developed with an enhanced chemiluminescence kit. Band intensity was determined by densitometry.

\section{Immunoprecipitation}

EPC lysates were prepared as just described. Five microgram of monoclonal antibody for the p 85 or p110 subunits of PI3K was added to $100 \mathrm{mg}$ protein and the suspension was gently rocked overnight $\left(4^{\circ} \mathrm{C}\right)$. Protein-antibody conjugates were precipitated with protein $\mathrm{A}$ beads and release of the precipitated protein achieved with $0.5 \%$ mercaptoethanol.

\section{Statistical Analysis}

Statistical significance was determined by one- or two-way analysis of variance and post hoc Student-Newman-Keuls tests. Significance was accepted at the $\mathrm{p}<0.05$ level. 

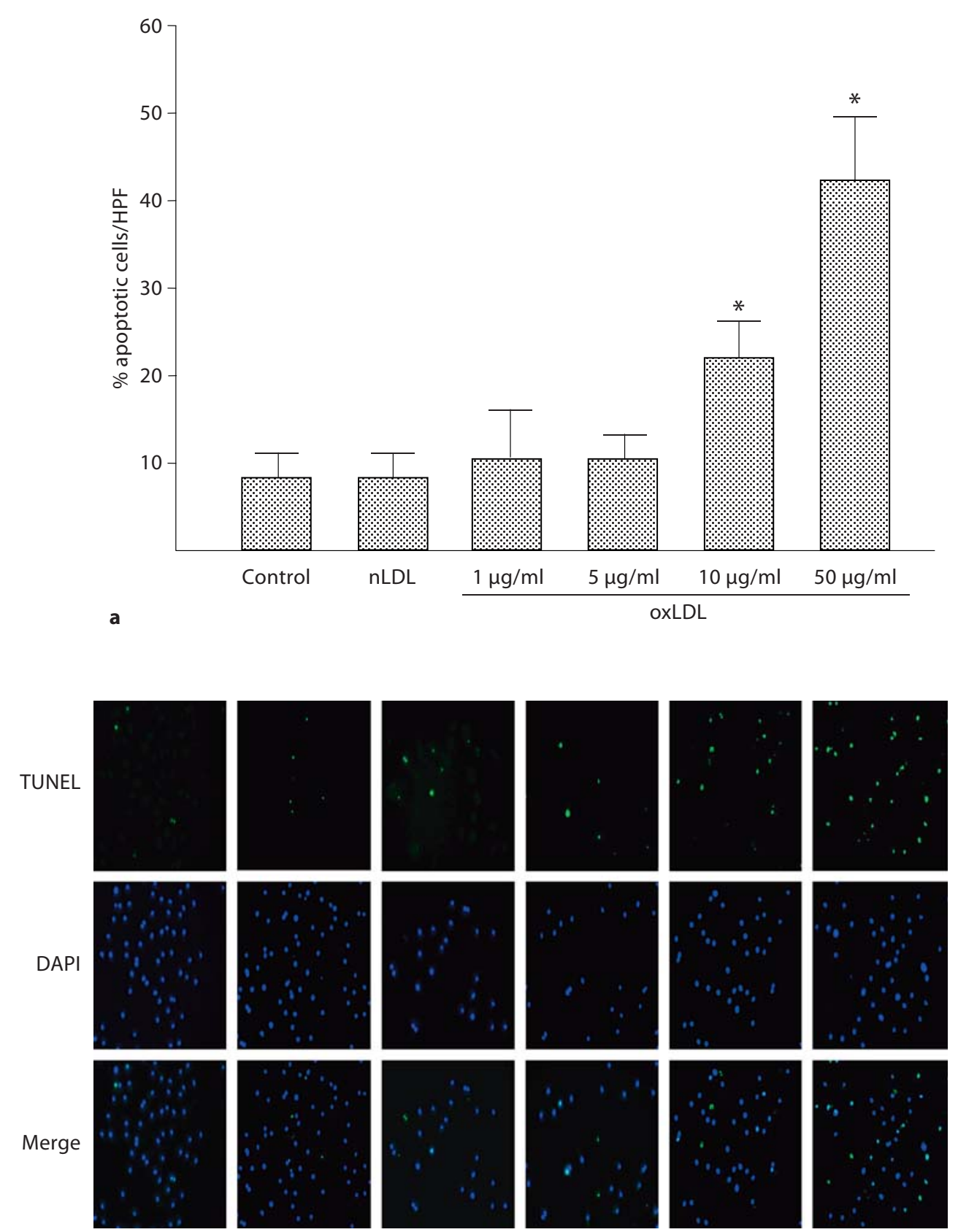

Control

$\mathrm{nLDL}$

b

$\frac{1 \mu \mathrm{g} / \mathrm{ml} \quad 5 \mu \mathrm{g} / \mathrm{ml} \quad 10 \mu \mathrm{g} / \mathrm{ml} \quad 50 \mu \mathrm{g} / \mathrm{ml}}{\text { oxLDL }}$

Fig. 2. Effects of nLDL and oxLDL on apoptosis in wild-type EPC. EPC cultures were exposed to nLDL $(10 \mu \mathrm{g} / \mathrm{ml})$ or oxLDL $(1-50$ $\mu \mathrm{g} / \mathrm{ml})$ in serum-free medium. The control well was treated with medium alone. a Percentage of apoptotic cells determined by
TUNEL staining. Data are presented as mean $\pm \mathrm{SD}, \mathrm{n}=3$ animals; ${ }^{*} \mathrm{p}<0.05$ oxLDL versus nLDL or control. b Representative series of immunofluorescent photomicrographs from a single EPC culture. All photos shown at $400 \times$. 


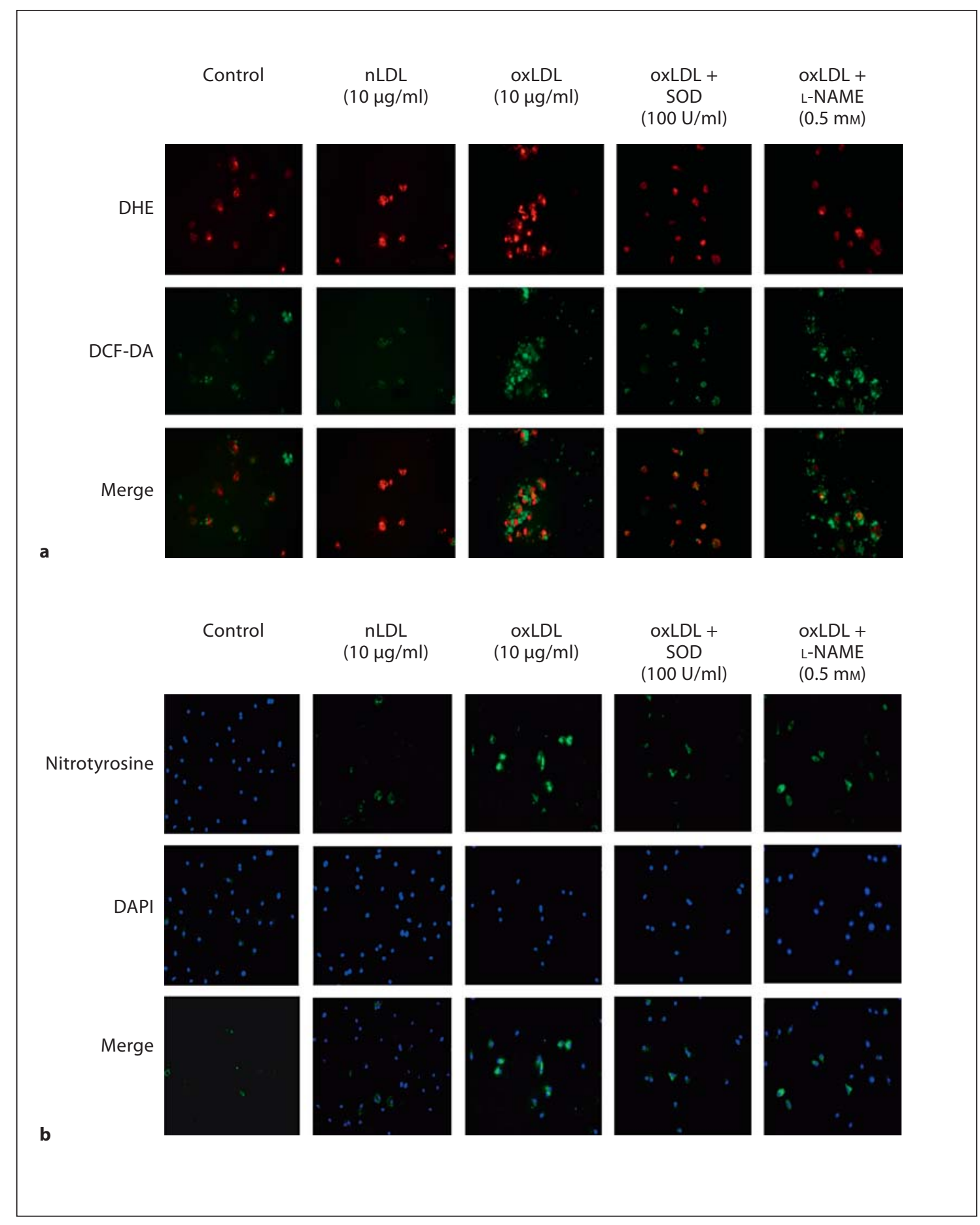

Fig. 3. Effects of nLDL and oxLDL on reactive oxygen species in wild-type EPC. EPC cultures were exposed to nLDL $(10 \mu \mathrm{g} / \mathrm{ml})$, oxLDL $(10 \mu \mathrm{g} / \mathrm{ml})$, oxLDL $(10 \mu \mathrm{g} / \mathrm{ml})+$ SOD $(100 \mathrm{U} / \mathrm{ml})$ or oxLDL $(10 \mu \mathrm{g} / \mathrm{ml})+\mathrm{L}-\mathrm{NAME}(0.5 \mathrm{mM})$ in serum-free medium. The control well was treated with medium alone. a Quantification of DCF and DHE staining in EPC. Data are presented as mean \pm SD, $n=$
$3 ;^{+} \mathrm{p}<0.05$ oxLDL versus $\mathrm{nLDL}$ or control; ${ }^{*} \mathrm{p}<0.05$ versus oxLDL. b Nitrotyrosine staining for protein nitrosylation. Nitrotyrosine is stained green. The slide was counterstained with DAPI to detect nuclei, which appears blue. This set of immunofluorescent photomicrographs is from a single experiment and are representative of three experiments. 
Fig. 4. Effects of SOD, L-NAME, epicatechin and FeTTPs on oxLDL-induced apoptosis in wild-type EPC. EPC cultures were exposed to nLDL $(10 \mu \mathrm{g} / \mathrm{ml})$ or oxLDL $(10 \mu \mathrm{g} / \mathrm{ml})$, or oxLDL $(10 \mu \mathrm{g} / \mathrm{ml})$ in the presence of SOD $(100 \mathrm{U} / \mathrm{ml})$, L-NAME $(0.5 \mathrm{mM})$, epicatechin $(100 \mu \mathrm{M})$ or FeTPPs $(2.5 \mu \mathrm{M})$ in serum-free medium. A control well was treated with serum-free medium alone. Apoptosis was determined by TUNEL staining. Data are expressed as the percentage of TUNEL positive cells with respect to the total number of cells (DAPI staining) per high power field. Data are presented as mean $\pm \mathrm{SD}, \mathrm{n}=3 ;{ }^{+} \mathrm{p}<0.05$ oxLDL versus nLDL or control; ${ }^{*} \mathrm{p}<0.05$ versus oxLDL.

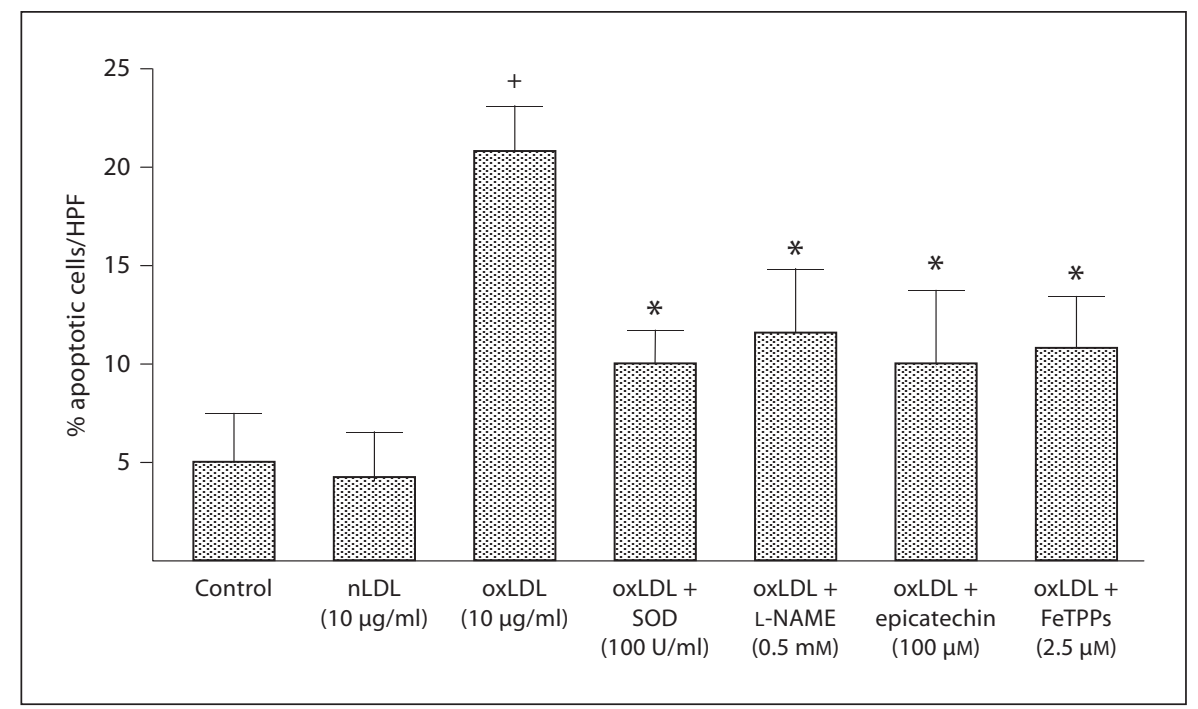

\section{Results}

Hypercholesterolemia is an important cardiovascular risk factor and has been shown to be associated with a reduction in the number of EPCs [6]. One mechanism that might contribute to this reduction is apoptosis [7]. To evaluate this possibility, we first established the extent of apoptosis in EPCs harvested from C57Bl/6 (WT) and ApoE mice ( $\mathrm{n}=3$ in each group). Spleen MNCs were sorted to obtain $\mathrm{CD} 34^{+}, \mathrm{KDR}^{+}$and $\mathrm{AC} 133^{+}$cells (EPCs) which were then cultured for $48 \mathrm{~h}$ in serum-free medium. EPC from $A p o E$ mice demonstrated a significantly greater percentage of apoptosis than WT mice (fig. 1a). Additionally, the ratio of p-Akt/Akt was significantly lower in EPC harvested from ApoE than from WT mice (fig. 1b). The presence of p-Akt is critical in EPC-mediated postischemic angiogenesis and is also important in preventing EPC apoptosis [11].

The generation of oxLDL is a critical determinant in many of the pathological consequences of hypercholesterolemia, including reduction in the number of circulating EPCs [14]. To evaluate the role of oxLDL in EPC dysfunction in hypercholesterolemia, we next determined the in vitro effects of oxLDL on apoptosis and reactive oxygen species in EPCs harvested from WT mice $(\mathrm{n}=3$ mice for EPC harvest). oxLDL induced EPC apoptosis in a dose-dependent manner with a threshold for effect of $10 \mu \mathrm{g} / \mathrm{ml}$; in contrast, nLDL $(10 \mu \mathrm{g} / \mathrm{ml})$ did not induce apoptosis (fig. 2a, b). oxLDL induces cell damage by inducing oxidative stress [7-10]. Thus, we next evaluated the effects of oxLDL on intracellular oxidant levels using the oxidant-sensitive fluoroprobes DCF and DHE, and evaluated the presence of oxidative stress by measuring nitrotyrosine in oxLDL-exposed EPCs. oxLDL $(10 \mu \mathrm{g} /$ $\mathrm{ml}$ ) increased the presence of $\mathrm{O}_{2}^{-}, \mathrm{H}_{2} \mathrm{O}_{2}$, and nitrotyrosine in WT EPCs (fig. 3a, b). Co-administration of oxLDL (10 $\mu \mathrm{g} / \mathrm{ml})$ with the antioxidant compounds SOD-PEG (100 $\mathrm{U} / \mathrm{ml})$, L-NAME $(0.5 \mathrm{mM})$, epicatechin $(100 \mu \mathrm{M})$ or FeTPPs $(2.5 \mu \mathrm{M})$ decreased oxLDL-induced production of reactive oxygen species (fig. 3a, b). Importantly, these antioxidant compounds also significantly reduced oxLDL-induced apoptosis (fig. 4). These findings indicate that oxLDL-induced oxidative stress and apoptosis are linked.

Akt is important in preventing EPC apoptosis and is impaired by oxidative stress [14]. Accordingly, we next determined the effects of oxLDL on the PI3K/Akt signal transduction system in WT EPCs under in vitro conditions ( $\mathrm{n}=3$ mice for EPC harvest). oxLDL caused a doseand time-dependent reduction in the ratio of $\mathrm{p}$-Akt/Akt with a threshold of effect noted at $10 \mu \mathrm{g} / \mathrm{ml}$ that was most evident 40 min after oxLDL administration (fig. 5a, b). SOD, L-NAME, epicatchein and FeTPPs significantly reduced the effect of oxLDL on the p-Akt/Akt ratio in WT EPCs (fig. 6).

PI3K consists of 2 subunits, p 85 and p110, that must remain associated for Akt to be functional [19]. Accordingly, we next evaluated the effect of oxLDL on PI3K subunits in WT EPCs ( $\mathrm{n}=3$ mice for EPC harvest). Immunoprecipitation of the PI3K subunits p85 or p110 followed by blotting for nitrotyrosine revealed that significant nitrosylation of the $\mathrm{p} 85$ subunit did not occur in 
Fig. 5. Time- and dose-response relationships between oxLDL and the expression of Akt and p-Akt in wild-type EPC. a EPC cultures were exposed to nLDL $(10 \mu \mathrm{g} / \mathrm{ml})$ or oxLDL $(1-50 \mu \mathrm{g} / \mathrm{ml})$ in serum-free medium; the control well was treated with serum-free medium alone. Density of the Akt and p-Akt bands were first corrected with respect to $\beta$-actin (not shown) and then the ratio of $\mathrm{p}$-Akt/total Akt expression calculated. The ratio of the wild-type group was assigned a value of 1.0. Data are presented as mean $\pm \mathrm{SD}, \mathrm{n}=3$; $^{* *} \mathrm{p}<0.01$ oxLDL versus nLDL or control. b EPC cultures were exposed to nLDL $(10 \mu \mathrm{g} / \mathrm{ml})$ or oxLDL $(10 \mu \mathrm{g} / \mathrm{ml})$ in serum-free medium for $0-80 \mathrm{~min}$; the control well was treated with serum-free medium alone. Density of the Akt and p-Akt bands were first corrected with respect to $\beta$-actin (not shown) and then the ratio of p-Akt/total Akt expression calculated. The ratio of the control group was assigned a value of 1.0. Data are presented as mean $\pm \mathrm{SD}, \mathrm{n}=3$; ${ }^{* *} \mathrm{p}<0.01$ oxLDL versus nLDL or control.
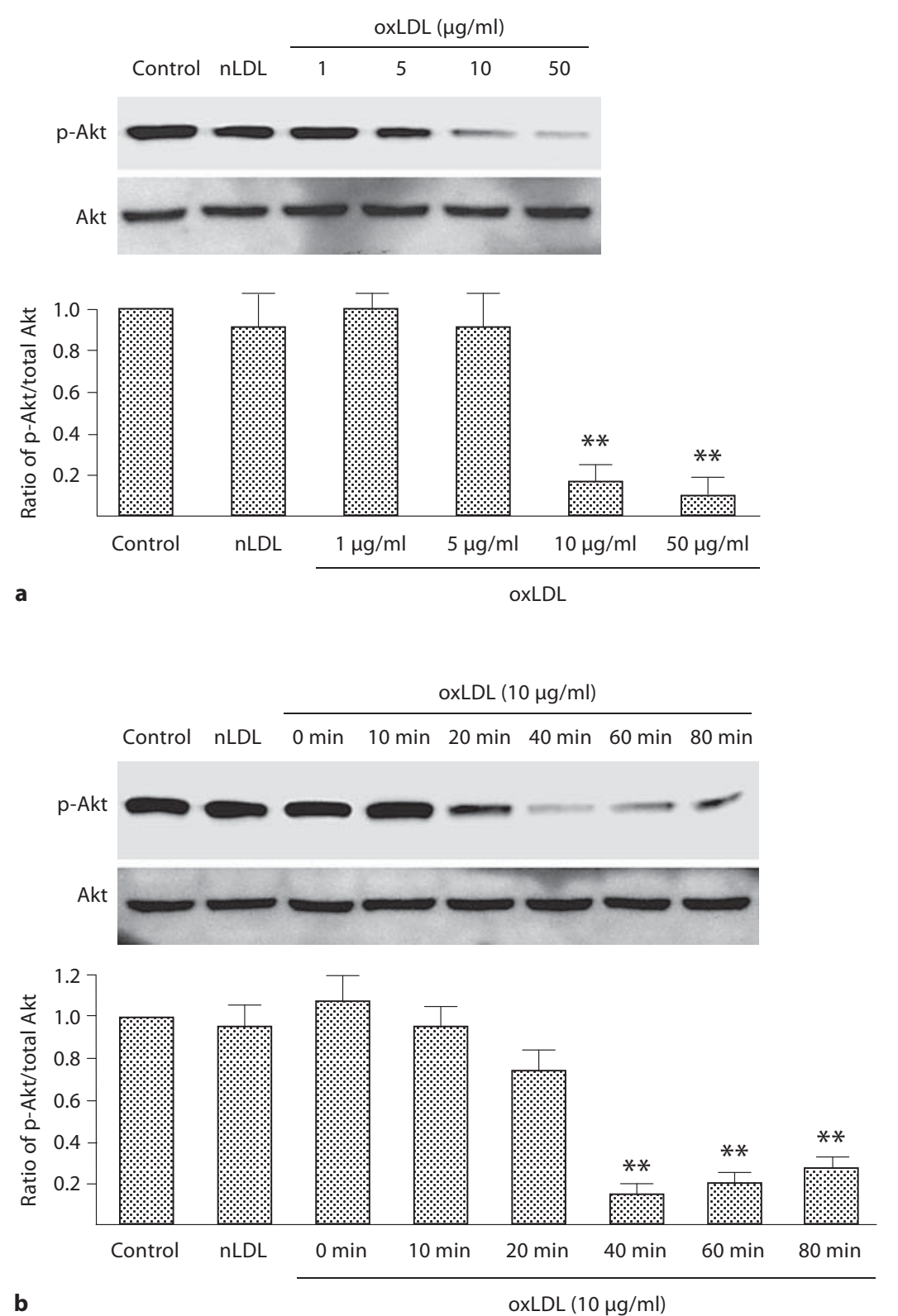

b

oxLDL $(10 \mu \mathrm{g} / \mathrm{ml})$ response to oxLDL (fig. 7a). In contrast, significant nitrosylation of the p85 subunit was evident in response to oxLDL (fig. 7b). Moreover, immunoprecipitation of the p110 subunit followed by blotting for the p85 and p110 subunits demonstrated that oxLDL induced a significant dissociation of the subunits (fig. 7c). oxLDL-induced nitrosylation of the p85 subunit and dissociation of the subunits were both significantly reduced by co-adminis- tration of SOD, L-NAME, epicatechin or FeTPPs. The greatest reduction in oxLDL-induced p85 nitrosylation was observed after co-administration of SOD (fig. 7b, c). These findings indicate that oxLDL interferes with Akt subunit association by nitrosylation of the p85 subunit. It is most likely that the effect of oxLDL on p85 nitrosylation and subsequent subunit dissociation contributed to the increased EPC apoptosis noted in WT EPCs in vitro, 
Fig. 6. Effects of SOD, L-NAME, epicatechin and FeTTPs on the ratio of p-Akt/total Akt in wild-type EPC. EPC cultures were exposed to nLDL $(10 \mu \mathrm{g} / \mathrm{ml})$ or oxLDL $(10 \mu \mathrm{g} / \mathrm{ml})$, or oxLDL $(10 \mu \mathrm{g} / \mathrm{ml})$ in the presence of SOD $(100 \mathrm{U} / \mathrm{ml}), \mathrm{L}-\mathrm{NAME}$ $(0.5 \mathrm{mM})$, epicatechin $(100 \mu \mathrm{M})$ or FeTPPs $(2.5 \mu \mathrm{M})$ in serum-free medium. A control well was treated with serum-free medium alone. Density of the Akt and p-Akt bands was first corrected with respect to $\beta$-actin (not shown) and then the ratio of p-Akt/ total Akt expression calculated. The ratio in the control group was assigned a value of 1.0. Data are presented as mean $\pm \mathrm{SD}$, $\mathrm{n}=3 ;^{+} \mathrm{p}<0.05$ oxLDL versus $\mathrm{nLDL}$ or control; * $\mathrm{p}<0.05$ versus oxLDL; ${ }^{*} \mathrm{p}<$ 0.01 versus oxLDL.

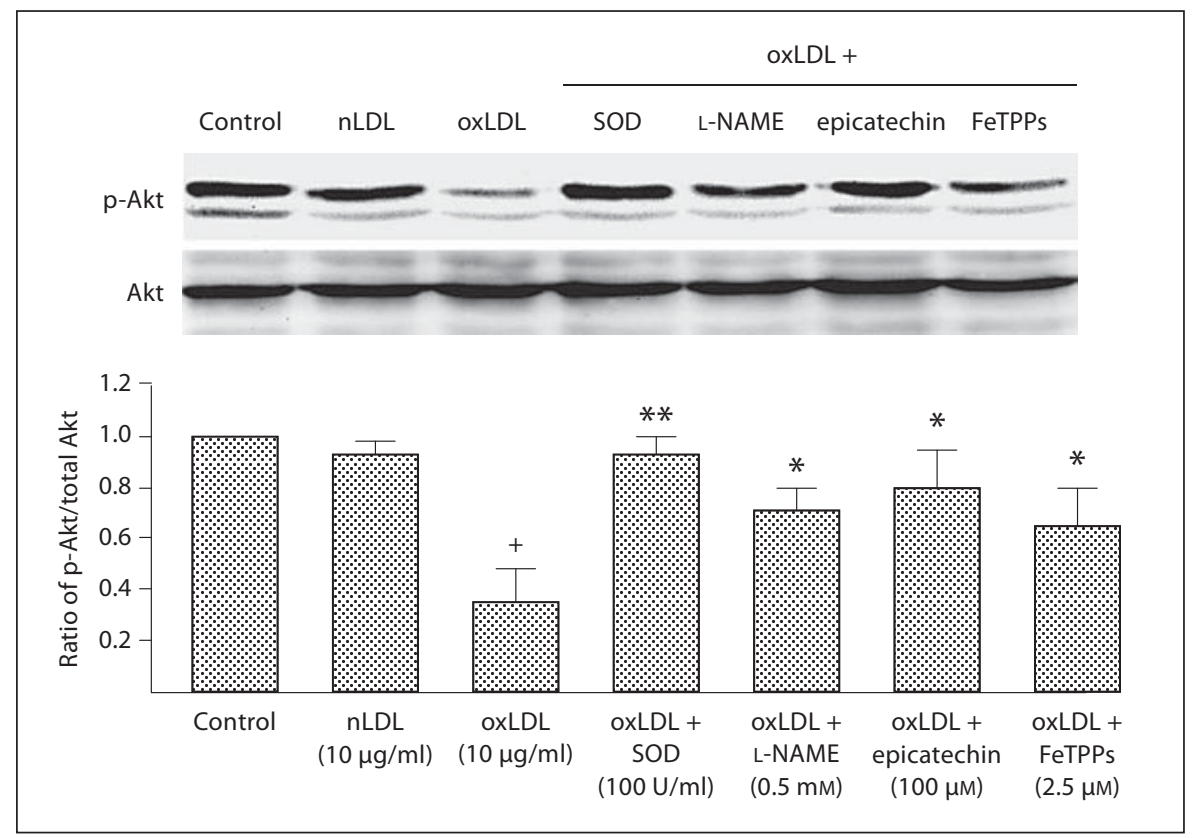

as well as the increased EPC apoptosis observed in ApoE mice in vivo.

Finally, we reasoned that if oxLDL-induced dysfunction of Akt were critical in the induction of oxLDL-induced EPC apoptosis, then transduction with a constitutively active isoform of Akt would prevent this apoptosis from occurring. To this end, we determined if transduction of WT EPCs with a constitutively active Akt (AdmyrAkt) altered the effect of oxLDL on EPC apoptosis. Transduction with an empty adenovirus vector (AdDLE1) served as the control and cultures from 3 mice were studied for each group. Ad-myrAkt significantly increased the ratio of p-Akt/Akt and induced phosphorylation of an established downstream target of Akt, glycogen synthase kinase $3 \alpha$, thus confirming successful transfection (fig. 8a). Ad-myrAkt significantly lowered oxLDLinduced EPC apoptosis, whereas it had no effect on the basal level of apoptosis in these cells (fig. 8b). This gainof-effect study design provides clear evidence that the Akt pathway is critical in preventing EPC oxLDL-induced apoptosis.

\section{Discussion}

Two novel findings were made in this investigation. First, ApoE mice demonstrated more than a threefold greater percentage of apoptotic EPCs within the spleno- cyte MNC population than did WT mice under in vivo conditions; moreover, EPCs from ApoE mice exhibited a significantly reduced p-Akt/Akt ratio compared to EPCs from WT mice. Second, application of exogenous oxLDL to WT EPCs under in vitro conditions caused nitrosylation of the p85 subunit of PI3K, as well as the dissociation of the p85 and p110 subunits. This in vitro effect was associated with a reduction of the EPC p-Akt/Akt ratio and an increase in EPC apoptosis, and the effect could be attenuated by transfection of EPCs with a constitutively active Akt. We thus propose that oxLDL-induced nitrosylation of the $\mathrm{p} 85$ subunit of PI3K is the mechanistic basis underlying disruption of the PI3K/Akt signaling pathway by oxLDL in EPCs and that this effect contributes to oxLDL-induced EPC apoptosis.

The PI3K/Akt signaling pathway is critical for function and survival of EPCs [11], based in large part on downstream activation of eNOS and subsequent production of NO [14, 18]. Mice genetically deficient in Akt [11] or eNOS [20] manifest reduced EPC function and compromised postischemic angiogenesis, effects that confirm an essential role for EPCs in postischemic vascular repair and adaptation [1-3]. Imanishi et al. [17] and Ma et al. [14] reported that oxLDL impairs EPC function via effects on Akt and eNOS, respectively. The present findings indicate that the oxLDL effects on Akt within EPCs are mediated indirectly, by an upstream disruption of PI3K, specifically via nitrosylation of the $\mathrm{p} 85$ subunit and subsequent dis- 
Fig. 7. Effects of SOD, L-NAME, epicatechin and FeTPPs on nitrotyrosine expression and the ratio of the PI3K p 85 and p110 subunits in wild-type EPC. EPC cultures were exposed to nLDL $(10 \mu \mathrm{g} / \mathrm{ml})$ or oxLDL $(10 \mu \mathrm{g} / \mathrm{ml})$, or oxLDL $(10 \mu \mathrm{g} / \mathrm{ml})$ in the presence of SOD $(100 \mathrm{U} / \mathrm{ml}), \mathrm{L}-\mathrm{NAME}$ $(0.5 \mathrm{mM})$, epicatechin $(100 \mu \mathrm{M})$ or FeTPPs $(2.5 \mu \mathrm{M})$ in serum-free medium. A control well was treated with serum-free medium alone. a The p110 Akt subunit was isolated by immunoprecipitation; the expression of p110 and nitrotyrosine was determined. Note the essential absence of nitrotyrosine. This set of Western blots is representative of 3 separate experiments. b The p 85 Akt subunit was isolated by immunoprecipitation; the expression of p110 and nitrotyrosine were determined. Density of the nitrotyrosine and PI3K p85 subunit bands were first corrected with respect to $\beta$-actin and then the ratio of nitrotyrosine/p85 expression calculated. The ratio of the control group was assigned a value of 1.0. Data are presented as mean $\pm \mathrm{SD}$, $\mathrm{n}=3 ;^{+} \mathrm{p}<0.05$ oxLDL versus $\mathrm{nLDL}$ or control; ${ }^{*} \mathrm{p}<0.05$ versus oxLDL; ${ }^{* *} \mathrm{p}<$ 0.01 versus oxLDL. c Density of the PI3K p110 and PI3K p85 subunit bands were first corrected with respect to $\beta$-actin and then the ratio of p85/p110 expression calculated. The ratio of the control group was assigned a value of 1.0. Data are presented as mean $\pm \mathrm{SD}, \mathrm{n}=3{ }^{+} \mathrm{p}<0.05$ oxLDL versus $\mathrm{nLDL}$ or control; ${ }^{*} \mathrm{p}<0.05$ versus oxLDL.

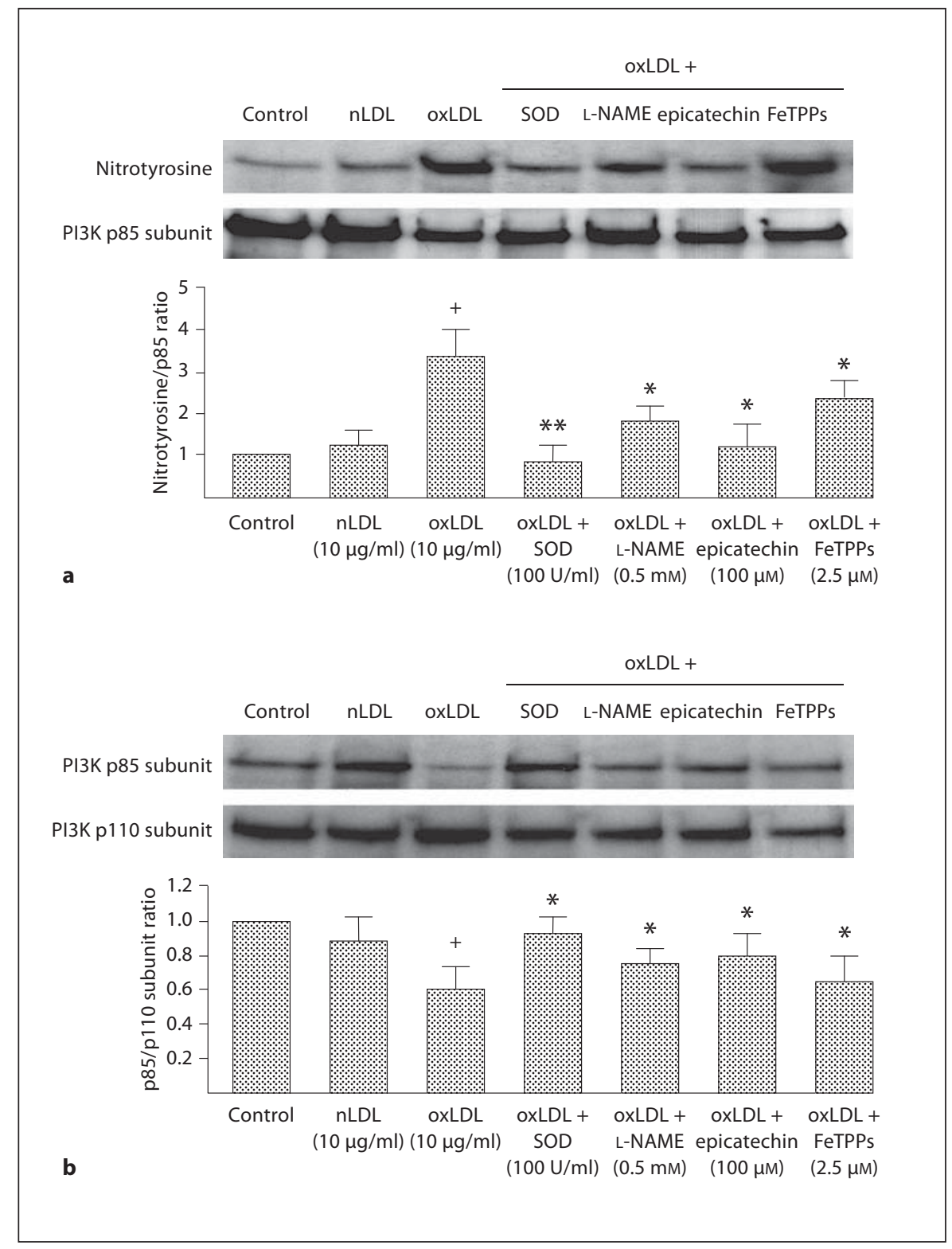

sociation of the p85 and p110 subunits. Dissociation of the p85 and p110 subunits of PI3K renders PI3K dysfunctional [19]. Transduction of WT EPCs with Ad-myrAkt, a constitutively active Akt isoform, significantly decreased the deleterious impact of oxLDL on the p-Akt/Akt ratio and lowered oxLDL-induced EPC apoptosis. The finding that Akt activation is critical for EPC survival is consistent with the reports of Llevadot et al. [21] and Lefèvre et al. [18] who demonstrated enhanced Akt activation and EPC function as well as survival following EPC treatment with the HMG-CoA reductase inhibitor simvastatin or the antioxidant resveratrol, respectively.
The present findings confirmed earlier reports that oxLDL generates intracellular oxidative stress [7-10]. Immunofluorescent imaging with the fluoroprobes DHE and DCF-DA demonstrated an increase in intracellular $\mathrm{O}_{2}^{-}$and $\mathrm{H}_{2} \mathrm{O}_{2}$ in EPC exposed to oxLDL in vitro; also, oxLDL-treated EPC exhibited increase nitrotyrosine, a finding that indicates the present of peroxynitrite generated by the reaction of $\mathrm{O}_{2}^{-}$with NO. The addition of exogenous peroxynitrite to RAW 264.7 cells [22] or microvascular endothelial cells [23] caused nitrosylation of the PI3K subunit p85. In this context, it is likely that peroxynitrite contributed to the nitrosylation of p85 in 


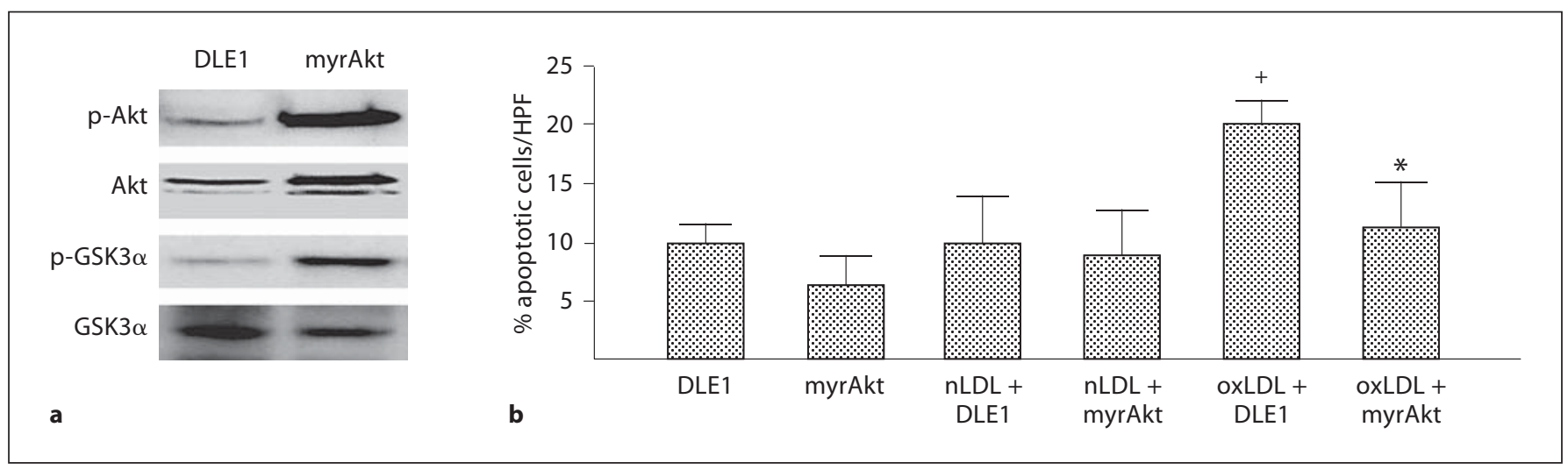

Fig. 8. Effects of myrAkt on nLDL- and oxLDL-induced apoptosis in wild type EPC. a Effects of Ad-DLE1 (control transduction) and Admiralty (constitutively active Akt transduction) on p-Akt, total Akt, p-GSK3 $\alpha$, total GSK3 $\alpha$ and $\beta$-actin expression in wildtype EPC. b EPC cultures, transducer with either Ad-DLE1 (control; empty vector) or Ad-myrAkt (constitutively active Akt) were exposed to $\mathrm{nLDL}(10 \mu \mathrm{g} / \mathrm{ml})$ or oxLDL $(10 \mu \mathrm{g} / \mathrm{ml})$, or oxLDL (10 $\mu \mathrm{g} / \mathrm{ml}$ ) in serum-free medium. Apoptosis was determined by TUNEL staining. Data are expressed as the percentage of TUNEL positive cells with respect to the total number of cells (DAPI staining) per high power field. Data are presented as mean $\pm \mathrm{SD}, \mathrm{n}=$ $3 ;^{+} \mathrm{p}<0.05$ oxLDL versus nLDL or control; * $\mathrm{p}<0.05$ Ad-myrAkt oxLDL versus Ad-DLE1 oxLDL.

FeTPPs is a metalloporphyrin that functions as an $\mathrm{OONO}^{-}$decomposition catalyst [29]. The presence of nitrotyrosine proves that $\mathrm{OONO}^{-}$was present in oxLDLtreated EPCs. The present findings indicate that specific elimination of $\mathrm{OONO}^{-}$effectively reduced oxLDL-induced EPC apoptosis. This improvement is not surprising in light of our finding that nitrosylation of the PI3K subunit $\mathrm{p} 85$ played a critical role in oxLDL-induced compromise of Akt activation in EPCs.

Although the focus of this work was on the effects of oxLDL on Akt and subsequent EPC apoptosis, it is clear that other signaling pathways are also important in this process. oxLDL induces a time- and dose-dependent increase in activation of p38 MAPK, while SB203580, a selective inhibitor of $\mathrm{p} 38 \mathrm{MAPK}$, significantly reduces oxLDL-induced apoptosis and in vitro functional deficiencies in EPCs [30]. Cross-talk between Akt and p38 MAPK occurs in mature endothelial cells, wherein Akt reduces p38 MAPK activation and so reduces endothelial cell apoptosis [31]. oxLDL also stimulates p53 activation of the proapoptotic protein Bax in differentiated EPCs [32], whereas oxidant-induced activation of Akt signaling reduces p53 activity in endothelial cells [32]. It is not presently known in cross-talk among the Akt, p38 MAPK and p53 signaling pathways occurs in EPC, although work to delineate these interactions is presently underway in our laboratory. 
EPCs participate in postischemic angiogenesis [1-3] and it has been proposed that autologous EPC transplant may be an effective therapeutic modality in the treatment of ischemic conditions, for example, coronary insufficiency and critical limb ischemia [34]. Indeed, studies in mice [35] as well as controlled human trials [36] support the feasibility of autologous EPC transplantation wherein EPCs would be harvested, expanded ex vivo, and then transfused back into the patient. A clear impediment to this approach, however, is that underlying diseases can impair the integrity of EPCs and thus potentially render them ineffective for autologous transfusion [37]. For example, conditions such as diabetes [38] and chronic ischemic heart disease [39] compromise EPC function and it is likely that these patient populations would comprise a substantial percentage of potential candidates for autologous EPC transplantation for ischemic vascular disease
[30]. In a similar context, Zhou et al. [40] reported that EPCs treated with oxLDL ex vivo displayed impaired function when transplanted into athymic nude mice following induction of hindlimb ischemia. The present findings indicate that oxLDL disrupts the critical PI3K/ Akt signaling pathway at the level of p 85 in EPCs, but that ex vivo treatment of these EPCs with SOD, L-NAME, epicatechin or FeTPPs reduces this effect and enhances EPC survival. This finding lends support to the concept that damaged EPCs might be successfully restored to effective function by ex vivo therapy

\section{Acknowledgement}

This work was supported by a grant from the National Heart, Lung, and Blood Institute (HL75353 to L.M.M.).

\section{References}

-1 Asahara T, Murohara T, Sullivan A, Silver M, van der Zee R, Li T, Witzenbichler B, Schatteman G, Isner JM: Isolation of putative progenitor endothelial cells for angiogenesis. Science 1997;275:964-967.

-2 Takahashi T, Kalka C, Masuda H, Chen D, Silver M, Kearney M, Magner M, Isner JM, Asahara T: Ischemia- and cytokine-induced mobilization of bone marrow-derived endothelial progenitor cells for neovascularization. Nat Med 1999;5:434-438.

$\checkmark 3$ Urbich C, Dimmeler S: Endothelial progenitor cells: characterization and role in vascular biology. Circ Res 2004;95:343-353.

4 Aicher A, Rentsch M, Sasaki K, Ellwart JW, Fändrich F, Siebert R, Cooke JP, Dimmeler S, Heeschen C: Nonbone marrow-derived circulating progenitor cells contribute to postnatal neovascularization following tissue ischemia. Circ Res 2007;100:581-589.

$\checkmark 5$ Gnecchi M, Zhang Z, Ni A, Dzau V: Paracrine mechanisms in adult stem cell signaling and therapy. Circ Res 2008;103:12041219.

-6 Werner N, Kosiol S, Schiegl T, Ahlers P, Walenta K, Link A, Böhm M, Nickenig G: Circulating endothelial progenitor cells and cardiovascular outcomes. N Engl J Med 2005;353:999-1007.

7 Salvayre R, Aug N, Benoist H, Negre-Salvayre A: Oxidized low-density lipoproteininduced apoptosis. Biochem Biophys Acta 202;1585:213-221.

8 Rueckschloss U, Galle J, Holtz J, Zerkowski $\mathrm{H}-\mathrm{R}$, Morawietz $\mathrm{H}$ : Induction of NAD(P)H oxidase by oxidized low-density lipoprotein in human endothelial cells. Circulation 2001;104:1767-1772.
-9 Fleming I, Mohamed A, Galle J, Turchanowa L, Brandes RP, Fisslthaler B, Busse R: Oxidized low-density lipoprotein increases superoxide production by endothelial nitric oxide synthase by inhibiting PKC $\alpha$. Cardiovasc Res 2005;65:897-906.

10 Hansen-Hagge TE, Baumeister E, Bauer T, Schmiedeke D, Renné T, Wanner C, Galle J: Transmission of oxLDL-derived lipid perioxide radicals into membranes of vascular cells is the main inducer of oxLDL-mediated oxidative stress. Atherosclerosis 2008;197: 602-611.

-11 Ackah E, Yu J, Zoellner S, Iwakiri Y, Skurk C, Shibata R, Ouchi N, Easton RM, Galasso G, Birnbaum MJ, Walsh K, Sessa WC: Akt1/ protein kinase $\mathrm{B} \alpha$ is critical for ischemic and VEGF-mediated angiogenesis. J Clin Invest 2005;115:2119-2127.

12 Boo YC, Jo H: Flow-dependent regulation of endothelial nitric oxide synthase: role of protein kinases. Am J Physiol 2003;285:C499C508.

-13 Aicher A, Heeschen C, Mildner-Rihm C, Urbich C, Ihling C, Technau-Ihling Z, Zeiher AM, Dimmeler S: Essential role of endothelial nitric oxide synthase for mobilization of stem and progenitor cells. Nat Med 2003;9: 1370-1376.

14 Ma FX, Zhou B, Chen Z, Ren Q, Lu SH, Sawamura T, Han ZC: Oxidized low density lipoprotein impairs endothelial progenitor cells by regulation of endothelial nitric oxide synthase. J Lipid Res 2006;47:1227-1237.
15 Dimayuga PC, Zhao X, Yano J, Chyu K-Y: Changers in immune responses to LDL epitopes during aging in hypercholesterolemic apoE(-/-) mice. Am J Physiol 2006;291: R1644-R1650.

16 Werner N, Junk S, Laufs U, Link A, Walenta K, Böhm M, Nickenig G: Intravenous transfusion of endothelial progenitor cells reduces neointima formation after vascular injury. Circ Res 2003;93:e17-e24.

- 17 Imanishi T, Hano T, Matsuo Y, Nishio I: Oxidized low-density lipoprotein inhibits vascular endothelial growth factor-induced endothelial progenitor cell differentiation. Clin Exp Pharmacol Physiol 2003;30:665-670.

$>18$ Lefèvre J, Michaud S-E, Haddad P, Dussault S, Ménard C, Groleau J, Turgeon J, Rivard A: Moderate consumption of red wine (cabernet sauvigon) improves ischemia-induced neovascularization in ApoE-deficient mice: effect on endothelial progenitor cells and nitric oxide. FASEB J 2007;21:3845-3852.

19 Leslie NR: The redox regulation of PI 3-kinase-dependent signaling. Antioxid Redox Signal 2006;8:1765-1774.

20 Murohara T, Asahara T, Silver M, Bauters C, Masuda H, Kalka C, Kearney M, Chen D, Chen D, Symes JF, Fishman MC, Huang PL, Isner JM: Nitric oxide synthase modulates angiogenesis in response to tissue ischemia. J Clin Invest 1998;101:2567-2578.

21 Llevadot J, Murasawa S, Kureishi Y, Uchida S, Masuda H, Kawamoto A, Walsh K, Isner JM, Asahara T: HMG-CoA reductase inhibitor mobilizes bone marrow-derived endothelial progenitor cells. J Clin Invest 2001; 108:399-405. 
-22 Hellberg CB, Boggs SE, Lapetina EG: Phosphatidylinositol 3-kinase in a target for protein tyrosine nitration. Biochem Biophys Res Commun 1998;252:313-317.

-23 El-Remessy AB, Bartoli M, Platt DH, Fulton $\mathrm{D}$, Caldwell RB: Oxidative stress inactivates VEGF survival signaling in retinal endothelial cells via PI 3-kinase tyrosine nitration. J Cell Sci 2005;118:243-252.

-24 Alderton WK, Cooper CE, Knowles RG: Nitric oxide synthases: structure, function and inhibition. Biochem J 2001;357:593-615.

-25 Kuzkaya N, Weissmann N, Harrison DG, Dikalov S: Interactions of peroxynitrite, tetrahydrobiopterin, ascorbic acid, and thiols. Implications for uncoupling of endothelial nitric-oxide synthase. J Biol Chem 2003;278: 22546-22554.

26 Steffan Y, Jung T, Klotz LO, Schewe T, Grune $\mathrm{T}$, Sies H: Protein modificaton elicited by oxidized low-density lipoprotein (LDL) in endothelial cells: protection by (-)-epicatechin. Free Rad Biol Med 2007;42:955-970.

-27 Lorenz M, Wessler S, Follmann E, Michaelis W, Düsterhöft, Baumann G, Stangl K, Stangl $\mathrm{V}$ : A constituent of green tea, epigallocatechin-3-gallate, activates endothelial nitric oxide synthase by a phosphatidylinositol-3$\mathrm{OH}$-kinase-, cAMP-dependent protein kinase-, and Akt-dependent pathway and leads to endothelial-dependent vasorelaxation. J Biol Chem 2004;279:6190-6195.

28 Jeong Y-J, Choi Y-J, Kwon H-M, Kang S-W, Park H-S, Lee M, Kang Y-H: Differential inhibition of oxidized LDL-induced apoptosis in human endothelial cells treated with different flavonoids. Br J Nutr 2005;93:581-591.
29 Misko TP, Highkin MK, Veenhuizen AW, Manning PT, Stern MK, Currie MT, Salvemini D: Characterization of the cytoprotective action of peroxynitrite decomposition catalysts. J Biol Chem 1998;273:1564615653.

30 Wu Y, Wang Q, Cheng L, Wang J, Lu G: Effect of oxidized low-density lipoprotein and function of endothelial progenitor cell mediated by p38 signal pathways. J Cardiovasc Pharmacol 2009;53:151-156.

31 Gratton J-P, Morales-Ruiz M, Kureishi Y, Fulton D, Walsh K, Sessa WC: Akt downregulation of $\mathrm{p} 38$ signaling provides a nove mechanism of vascular endothelial growth factor-mediated cytoprotection in endothelial cells. J Biol Chem 2001;276:30359-30365.

32 Cheng J, Cui R, Chen C-H, Du J: Oxidized low-density lipoprotein stimulates p53-dependent activation of proapoptotic Bax leading to apoptosis of differentiated endothelial progenitor cells. Endocrinology 2007;148: 2085-2094.

33 Niwa K, Inanami O, Yamamori T, Ohta T, Hamasu T, Kuwabara M: Redox regulation of PI3K/Akt and p53 in bovine aortic endothelial cells exposed to hydrogen peroxide. Antioxid Redox Signal 2003;5:713-722.

34 Asahara T, Kalka C, Isner JM: Stem cell therapy and gene transfer for regeneration. Gene Ther 2000;7:451-457.
35 Kalka C, Masuda H, Takahashi T, KalkaMoll WM, Silver M, Kearney M, Li T, Isner JM, Asahara T: Transplantation of ex vivo expanded endothelial progenitor cells for therapeutic neovascularization. Proc Natl Acad Sci 2000;97:3422-3427.

36 Huang P, Xiao Z, Li S, Yang R, Han M, Han $\mathrm{ZC}$ : Autologous transplantation of granlocyte colony-stimulating factor-mobilized peripheral blood mononuclear cells improves critical limb ischemic in diabetes. Diabetes Care 2005;28:2155-2160

37 Werner N, Nickenig G: Influence of cardiovascular risk factors on endothelial progenitor cells. Limitations for therapy? Arterioscler Thromb Vasc Biol 2006;26:257-266.

38 Tepper O, Galiano RD, Capla JM Kalka C, Gagne PU, Jacobowitz GR, Levine JP, Gurtner GC: Human endothelial progenitor cells from type II diabetics exhibit impaired proliferation, adhesion and incorporation into vascular structures. Circulation 2002;106: 2781-2786.

39 Heeschen C, Lehmann R, Honold J, Assmus B, Aicher A, Walter DH, Martin H, Zeiher AM, Dimmeler S: Profoundly reduced neovascularization capacity of bone marrow mononuclear cells derived from patients with chronic ischemic heart disease. Circulation 2004;109:1615-1622.

40 Zhou B, Ma FX, Liu PX, Fang ZH, Wang SL, Han ZB, Poon M-C, Han ZC: Impaired therapeutic vasculogenesis by transplantation of oxLDL-treated endothelial progenitor cells. J Lipid Res 2007;48:518-527. 